\title{
Blood Lead influences the anemia status of malaria infected children in Katanga Kampala Uganda.
}

Authors; Ambrose Mukisa ${ }^{1}$, Denis Kasozi ${ }^{1}$, Claire Aguttu ${ }^{1}$, Peter C. Vuzi ${ }^{1}$, Florence Nantaba ${ }^{2}$, Joseph Kyambadde* 1

1. Department of Biochemistry and Sports Science, College of Natural Sciences, Makerere University

2. Department of Chemistry, College of Natural Sciences, Makerere University

* Corresponding author

\begin{abstract}
Lead pollutants mainly from urban agricultural practices, Leaded paints, Leaded fuels spillages, Leadcontaminated air, soils, and water sources pause a health threat to urban children in Uganda. Prolonged Lead exposure affects iron metabolism, by competitively blocking iron absorption leading to anemia. Blood Lead (BL) inhibits key enzymes ferrochelatase and aminolevulinic acid dehydrogenase (ALAD) involved in hemoglobin $(\mathrm{Hb})$ biosynthesis even at very low levels. Lead poisoning and malaria infection geographically overlap, and both produce similar hematological outcome especially in children. Malaria parasites cause anemia by destroying parasitized red blood cells, therefore, co-existence of BL and malaria parasites infection, worsens the anemia status of the host. This study aimed at expounding the extent of heme synthesis inhibition by BL levels among a study group of malaria positive children by measuring levels of free erythrocyte protoporphyrin (FEP) in blood samples.
\end{abstract}

Briefly venous blood samples from 198 children were analyzed for malaria parasite densities by the thick smear method, hemoglobin $(\mathrm{Hb})$ concentrations determined by the standard cyan methemoglobin method, BLL were analyzed on an atomic absorption spectrophotometer and FEP levels were fluorometrically measured.

The results showed means of BLL $(9.3 \mu \mathrm{g} / \mathrm{dL}), \mathrm{Hb}(7.5 \mathrm{~g} / \mathrm{dL}), \mathrm{FEP} / \mathrm{Hb}(8.3 \mu \mathrm{g} / \mathrm{g})$ and parasite density (PD) $\left(3.21 \times 10^{3}\right.$ parasites $\left./ \mu \mathrm{L}\right)$ among the study group. A majority of $151 / 198(76.3 \%)$ of the children were moderately anemic while 8/198 (4\%) were severely anemic. There was weak correlation between PD and $\mathrm{Hb}\left(\mathrm{R}^{2}=-0.15\right.$, P-value < 0.001), as compared to one between $\mathrm{FEP} / \mathrm{Hb}$ and $\mathrm{Hb}\left(\mathrm{R}^{2}=-0.6, \mathrm{P}\right.$-value=0.001). The study conclude that BL is a significant contributor to malaria anemia and should be considered in management of anemia in malaria endemic areas.

Keywords; Blood Lead, Plasmodium malaria parasites, Anemia, Free erythrocytes protoporphyrin. 


\section{Introduction}

Like many malaria halo endemic developing countries, Uganda is faced with several health -threatening diseases including anemia. A majority (60\%) of the Uganda's urban dwellers live in slums such as Katanga [1] in Kampala capital city where social disadvantages remain a big problem [30]. Due to the poor urban planning of Kampala city, there are no gazetted residential areas so people live in or next to industries, workshops, motor garages, metal crafts yards, battery recycling plants, motor garages, mosquito breeding grounds, and landfills which predisposes them to lead intoxication [32]. There are reports of elevated lead levels in water sources, soils, foodstuffs and air around Kampala city [2]. According to the study done by [3], Plasmodium malaria accounts for up to $40 \%$ of all outpatient visits, $25 \%$ of all hospital admissions, and $14 \%$ of all hospital deaths $[4,15]$ despite the government efforts to curb its transmission [15]. $53 \%$ of the children in this area especially those under the age of 5 years have been reported to be anemic $[3,5]$ and this could be due to high malaria prevalence in this area.

Although, malaria infections remain the key cause of the high prevalence of anemia, there are maybe other neglected cofounders like Lead poisoning resulting from contaminated air, soils, water sources, urban-grown foodstuffs and Leaded paints $[2,6,7,8]$. Because both lead pollution and malaria geographically overlap, and produce similar hematological outcomes their co-existence in this area may affect the child's health [28].

Lead exposure accounts for an individual's blood lead level (BLL) and is more evident in developing fetus by directly affecting the hematopoietic system. Erythrocytes are the major sink of over $99 \%$ of the Lead present in the blood and with over $80 \%$ is bound to $\delta$-aminolevulinic acid dehydratase ( $\delta$-ALAD) a cytosolic enzyme. This enzyme is believed to catalyze the formation of porphobilinogen from $\delta$-aminolevulinic acid (ALA) $[9,10]$.

During lead intoxication, BL is believed to limit the iron transfer from endosomes toward the cytoplasm and to reduce the lifespan of circulating erythrocytes by increasing the fragility of cell membranes [11, 12].

Blood lead further triggers a reduction in red blood cells (RBC) production by specifically inhibiting Ferrochelatase a mitochondrial enzyme that catalyzes the insertion of iron into protoporphyrin during heme formation. Aminolevulinic acid synthetase (ALAS) a mitochondrial enzyme that catalyzes the formation of aminolevulinic acid (ALA) from succinyl CoA and glycine is also affected by BL.

In a normal heme synthesis system, the rate of iron formation and utilization is well balanced and equilibrium is altered by insufficiency of iron. High malaria burden, overproduction of protoporphyrin and decreased ferrochelatase activity due to Lead poisoning could be responsible for the high anemia scourge. 
During malaria anemia, Lead becomes even more concentrated in red blood cells causing deleterious effects on several essential cellular processes, including inhibition of protein synthesis. Malaria due to Plasmodium infections becomes fatal by causing severe anemia to the host though other symptoms may occur depending on the species.

Malarial anemia is caused by massive erythrocytes lysis due to elevated parastemia resulting in parasitized red cells rupture. Because of increased parasite density in the host system, there are intrinsic and extrinsic changes to the red blood cells. This persistent situation in turn activates the splenic and other macrophages for phagocytosis [13] and resulting into anemia.

Both iron deficiency due to malaria and BL are each capable of inhibiting heme synthesis at the final step but low cellular iron concentrations during iron deficiency enhance Lead's inhibition on synthetic reactions because of its high affinity for the side chains of some amino acids than iron.

Ferrochelatase is specifically sensitive to low iron levels in the presence of Lead poisoning [14] and zinc instead of iron is incorporated into protoporphyrin (PPN) resulting in elevated levels of zinc protoporphyrin (ZPP).

Zinc protoporphyrin or FEP concentrations have been used to measure of heme synthesis inhibition, and increased levels are an indicator of iron deficiency as a heme synthesis disorders [15].

Since red cells are at the Centre of anemia pathogenesis, elevated malaria parasite density and BLL could produce severe anemia among children. The severity of anemia status is dependent on the host's age and nutrition status [16]. The combined aftermath of these two processes in malaria-endemic regions may result in severe anemia. This work, therefore, aimed at finding the association between blood lead levels and Plasmodium parasite density and anemia status among the study group. In this study, reduced hemoglobin $\mathrm{Hb}$ concentration was considered an index of anemia while the FEB/Hb ratio as an impaired heme synthesis index due to Lead poisoning.

\section{METHODS}

This was a cross-sectional study on children aged 6 -60months living in Katanga area- Kampala city. The study was approved by Gulu University Research Ethics Committee No. (GUREC-048) and Parent/Guardian fully signed consent forms. The children were first screened for Plasmodium parasite infection before recruitment. $5 \mathrm{mls}$ of venous blood from 198 malaria positive children were collected into EDTA by Qualified nurses and technicians. The samples were then transported on ice to Makerere 
University Biochemistry Department laboratory and stratified according to malaria parasite density. The samples were then kept at $4^{0} \mathrm{C}$ awaiting various analysis and determinations.

\section{Determination of Parasite density by thick smear method}

Thick smears were prepared as described by [17], air dried, stained with 10\% Leishman without fixing and examined under a CX 21 Olympus microscope. Five hundred leukocytes plus the number of malaria parasites seen in the same field were recorded. The number of malaria parasites per microliter (parasite/ $\mu \mathrm{L}$ ) of blood was expressed as the reciprocal of the mean counts in the three slides divided by the leukocyte counts, multiplied by a factor of 8000 i.e.

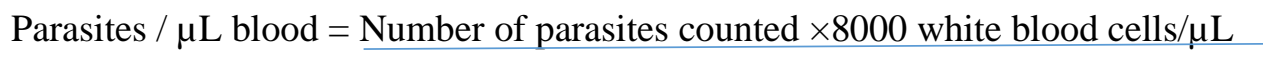

No. of white blood cells count

\section{Determination of blood lead levels by atomic absorption spectrometry}

BLL were determined using an atomic absorption spectrophotometer (Agilent 2000 series) equipped with a graphite tube atomizer and deuterium background correction facility. A hollow-cathode Lead lamp with a working current of $5 \mathrm{~mA}, 283.3 \mathrm{~nm}$ spectral line and $0.5 \mathrm{~nm}$ bandwidth was used. Aliquots $(500 \mu \mathrm{l})$ of whole blood melted with $1.2 \mathrm{ml}$ of $0.5 \%$ Triton X-100 and $1 \%\left(\mathrm{NH}_{4}\right)_{2} \mathrm{HPO}_{4}$ solution were added to $1.8 \mathrm{ml}$ of deionized water and $1.5 \mathrm{ml}$ of $20 \%$ Trichloroacetic acid (TCA) and vortex mixed. The samples were centrifuged for $20 \mathrm{~min}$ at $5000 \mathrm{rpm}$ and $10 \mu \mathrm{l}$ of the supernatant injected onto the graphite tube. The calibration curve was drawn using a standard addition method as described in M-572 of INSPQ's Toxicology Laboratory method.

\section{Fluorospectrophotometric quantification of free erythrocyte protoporphyrins}

The FEP was measured following a method described by [18] using a fluorospectrophotometer set at 405nm excitation $610 \mathrm{~nm}$ emissions. The porphyrins were extracted by adding $20 \mu \mathrm{l}$ aliquots of whole blood to a solution containing $100 \mu \mathrm{L}$ of $10 \%$ ammonium sulfate and 5\% celite and vortex mixed for 10 sec. $400 \mu \mathrm{l}$ of $95 \%$ ethanol was then added and vortex mixed for more 20 seconds. This was followed by addition of $600 \mu \mathrm{l}$ of acetone and further vortex mixing for $20 \mathrm{sec}$. All the samples were put on an ice bath for $20 \mathrm{~min}$, vortex mixed for $20 \mathrm{sec}$. and centrifuged at $4^{\circ} \mathrm{C}$ for $10 \mathrm{~min}$. The supernatants were harvested into small borosilicate tubes and aliquots of $300 \mu \mathrm{l}$ mixed with $300 \mu \mathrm{l}$ of a solution containing propylene glycol and 1.5 N HCI, (4:1) and let to stand for $20 \mathrm{~min}$ before reading at $405 \mathrm{~nm}$ excitation and 610 emissions. The FEP blood concentration was calculated using the following formulae;

$$
\mathrm{FEP}(\mu \mathrm{g} / \mathrm{dL} \text { Blood })=\mathrm{FEP} \mu \mathrm{g} / 100 \mathrm{ml} \text { extract }=\frac{\mathrm{F}_{\mathrm{z}} \times \mathrm{C}_{\mathrm{s}} \times 2.7 \times 100}{\mathrm{~F}_{\mathrm{s}} \times 1.1 \times 0.2}
$$


Where Fz is the sample fluorescence, Cs concentration of the standard, Fs is the fluorescence of the standard, 2.7 is the final volume of $\mathrm{HCl}$ phase, 100 is the conversion factor to $100 \mathrm{ml}$ of extract, 1.1 conversion factor for protoporphyrin measured against a coproporphyrin standard and $0.2(20 \mu 1)$ is the original blood volume measured. The FEP/Hb ratio expressed as microgram $\mathrm{Hb}$ per gram $\mathrm{Hb}$ was calculated by dividing the FEP/dL RBC by gram $\mathrm{Hb} / \mathrm{dL}$.

\section{Colorimetric determination of hemoglobin levels by blood cyan methemoglobin reaction method}

Hemoglobin levels were determined by cyan methemoglobin reaction method, where $100 \mu$ laliquots of samples were made to a total volume of $1000 \mu \mathrm{l}$ with reaction solution containing $200 \mathrm{mg}$ of hexacyanoferrate III, $50 \mathrm{mg}$ of potassium cyanide, $140 \mathrm{mg}$ of potassium hydrogen phosphate and $1 \mathrm{ml}$ of Triton X-100 in a liter of distilled water), and incubated for $15 \mathrm{~min}$ at room temperature before reading at $540 \mathrm{~nm}$. The blank was the reaction reagent. $500 \mu \mathrm{l}$ of standard hemoglobin standard $(0.7 \mathrm{mg} / \mathrm{ml})$ diluted with $500 \mu \mathrm{l}$ of the same reagent and treated as above was also read. The Hb concentration in $\mathrm{g} / \mathrm{dl}$ was calculated using formula;

$\mathrm{Hb}$ concentration $(\mathrm{g} / \mathrm{dL})=$ OD sample $\times$ concentration of the standard $(\mathrm{mg} / \mathrm{dL})$

OD standard sample

Where OD =optical density or absorbance at 540nm

\section{Results}

Of the 198 children enrolled in the study, 8/198 (4\%) of the children were severely anemic with $\mathrm{Hb}<$ $5 \mathrm{~g} / \mathrm{dL}$, mean parasite density $=7.4 \times 10^{3}$ parasites $/ \mu \mathrm{L}$, mean $\mathrm{BLL}=9.2 \pm 4.3 \mu \mathrm{g} / \mathrm{dL}$,

Mean FEP/Hb $=7.4 \pm 2.9 \mu \mathrm{g} / \mathrm{g}$. 39/198 (19.7\%) of the study group were not anemic with a mean value of $\mathrm{Hb}>10 \mathrm{~g} \mathrm{Hb} / \mathrm{dL}$ (above the WHO cut off point), mean parasite density $=1.7 \times 10^{3}$ parasites $/ \mu \mathrm{L}$, mean BLL $<2 \mu \mathrm{g} / \mathrm{dL}$, Mean $\mathrm{FEP} / \mathrm{Hb}=7.4 \pm 2.9 \mu \mathrm{g} / \mathrm{g}$. The details of the distribution are shown in table 1 . 
Table. Showing the mean parasite density, mean hemoglobin levels, mean BLL distribution among the 198 children that participated in the study.

\begin{tabular}{|l|l|l|l|l|}
\hline $\begin{array}{l}\text { Mean parasite } \\
\text { density/ } \mu \mathrm{L} \\
\times 10^{3}\end{array}$ & $\begin{array}{l}\text { No. of } \\
\text { samples } \\
\mathrm{N}\end{array}$ & $\begin{array}{l}\text { Mean } \\
\mathrm{BLL} \\
\mu \mathrm{g} / \mathrm{dL}\end{array}$ & $\begin{array}{l}\text { Mean } \\
\mathrm{FEP} / \mathrm{Hb} \\
\mu \mathrm{g} / \mathrm{g}\end{array}$ & $\begin{array}{l}\mathrm{g} / \mathrm{dL} \\
\end{array}$ \\
\hline $0.1-1.1$ & 16 & $10.3 \pm 1.9$ & $7.9 \pm 3$ & $7.0 \pm 3.2$ \\
\hline $1.2-2.2$ & 39 & $<2$ & 0.6 & $10.4 \pm 2.7$ \\
\hline $2.3-3.3$ & 42 & $10.3 \pm 1.7$ & $2.9 \pm 3.2$ & $8.5 \pm 3.1$ \\
\hline $3.4-4.4$ & 35 & $7.9 \pm 2.1$ & $3.9 \pm 2.8$ & $9.2 \pm 3.0$ \\
\hline $4.5-5.5$ & 34 & $7.9 \pm 1.8$ & $8.4 \pm 3.2$ & $9.3 \pm 4.1$ \\
\hline $5.6-6.6$ & 23 & $6.4 \pm 1.8$ & $4.9 \pm 2.7$ & $6.8 \pm 3.3$ \\
\hline $6.7-7.7$ & 8 & $9.7 \pm 5.2$ & $7.4 \pm 2.0$ & $4.9 \pm 2.9$ \\
\hline $7.8-8.8$ & 1 & 5.1 & 5.53 & 6.7 \\
\hline
\end{tabular}

$\mathrm{Hb}=$ hemoglobin, $\mathrm{BLL}=$ blood lead levels, $\mathrm{FEP}=$ Free erythrocyte protoporphyrin

Table 2. Pearson's correlation and p-values of the among different interacting variables

\begin{tabular}{|l|l|l|}
\hline Interacting variables & $\begin{array}{l}\text { Correlation } \\
\text { values }\end{array}$ & -value \\
\hline $\begin{array}{l}\text { Parasite density and } \\
\mathrm{Hb}\end{array}$ & -0.1497 & 0.035 \\
\hline $\mathrm{Hb}$ and $\mathrm{BLL}$ & 0.552 & $<0.001$ \\
\hline $\mathrm{Hb}$ and FEP/Hb & -0.572 & $<0.001$ \\
\hline $\begin{array}{l}\mathrm{BLL} \text { and Parasite } \\
\text { density }\end{array}$ & 0.124 & 0.082 \\
\hline $\begin{array}{l}\mathrm{FEP} / \mathrm{Hb}, \text { Parasite } \\
\text { density and } \mathrm{Hb}\end{array}$ & 0.377 & $<0.001$ \\
\hline
\end{tabular}




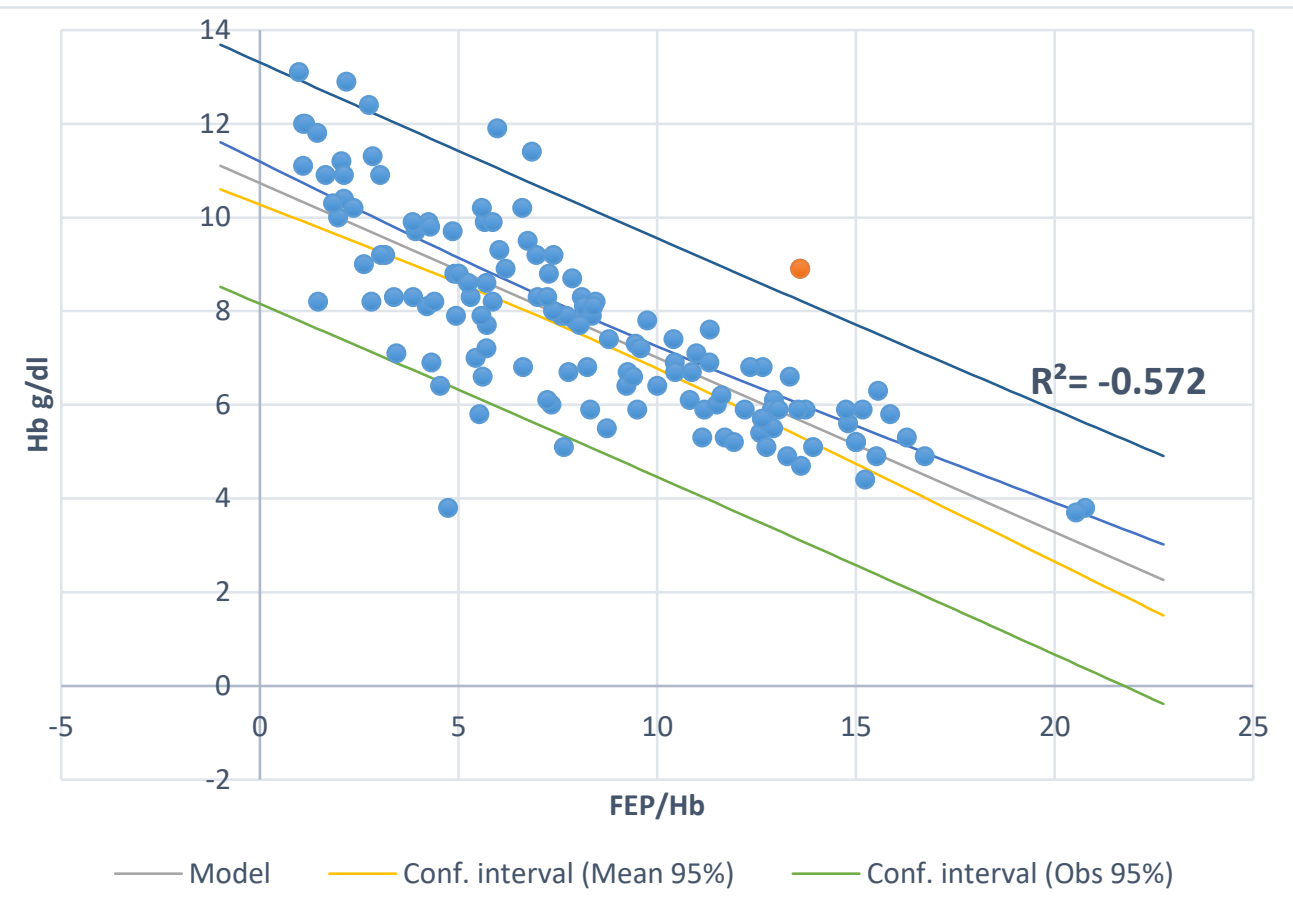

Figure 1 Regression curve showing how FEP/Hb levels relates with hemoglobin levels of malaria infected children.

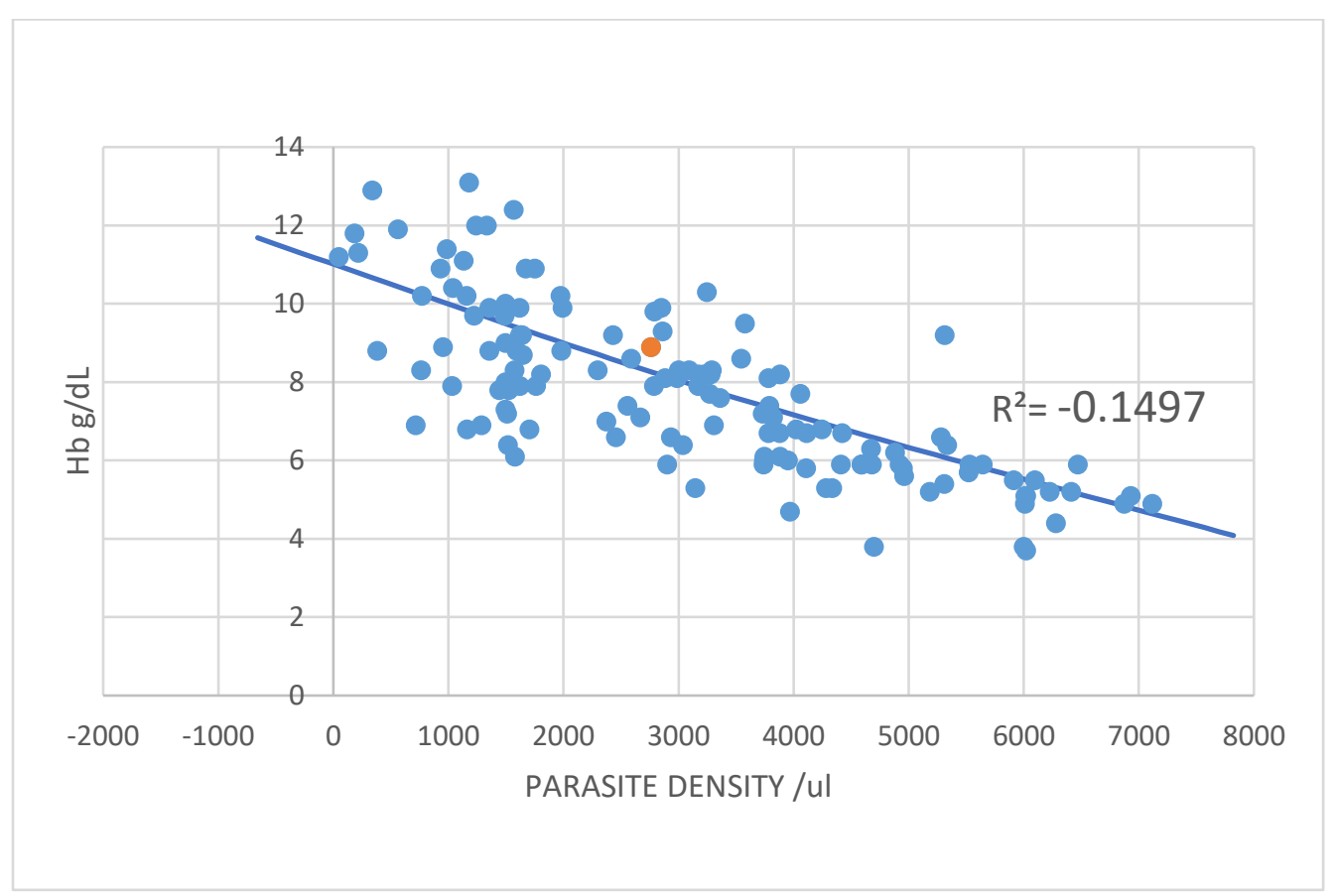

Figure 2. Scatter graph showing how parasite density relates with hemoglobin levels of malaria infected children. 


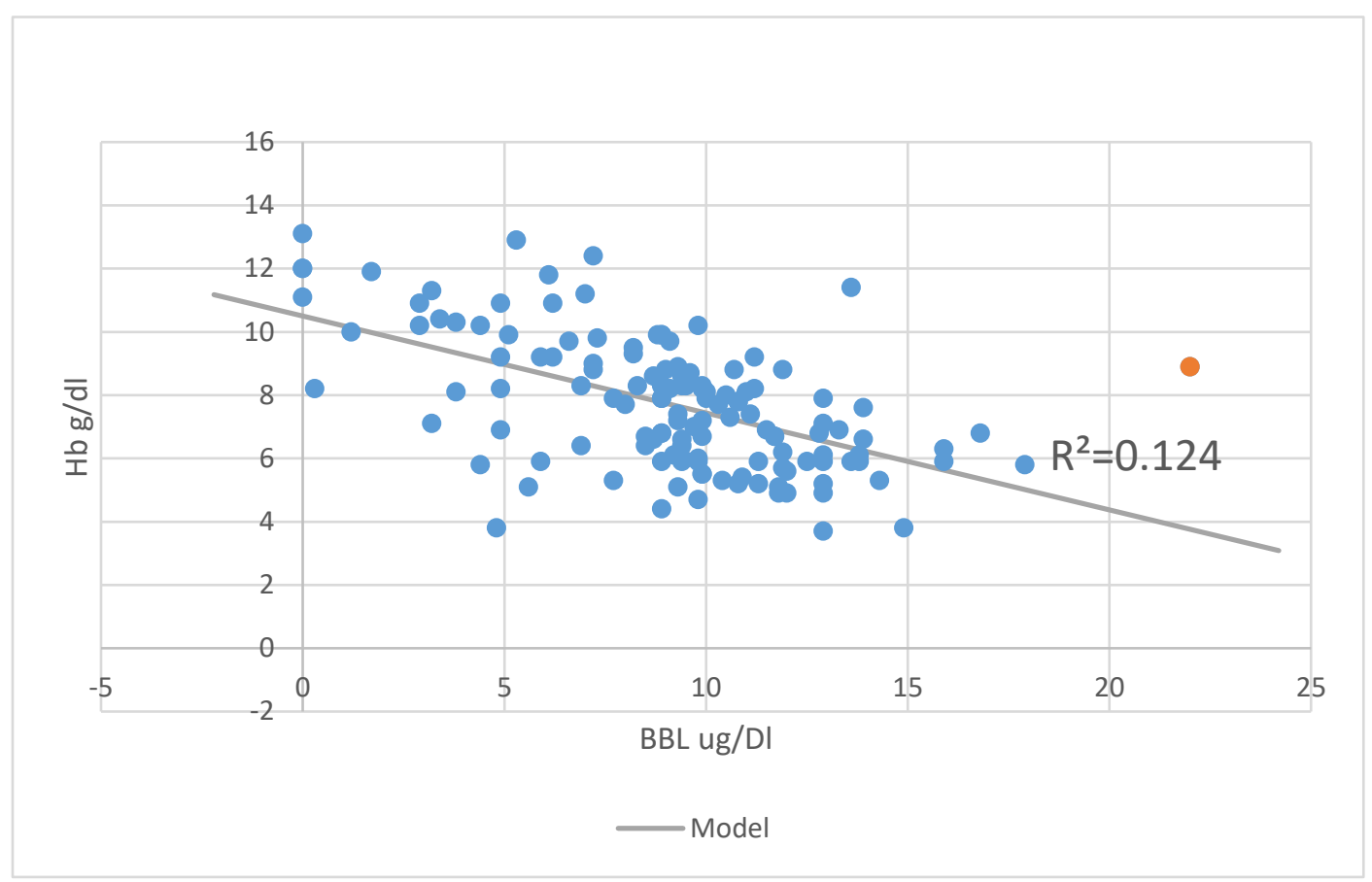

Figure 3 Scatter graph showing how BBL levels relates with hemoglobin levels of malaria infected children.

\section{Discussion}

The research results shows the means of blood lead level $(\mathrm{BLL})=9.3 \mathrm{ug} / \mathrm{dL}$, a mean parasite density $=$ $3.21 \times 103$ parasite $/ \mu \mathrm{L}$, mean $\mathrm{Hb}=7.5 \mathrm{~g} / \mathrm{dL}$ and a mean $\mathrm{FEP} / \mathrm{Hb}$ ratio $=8.7 \mu \mathrm{g} / \mathrm{g}$ across the 198 children recruited in this study. Whereas only $4 \%$ of the children had a BLL of $>10 \mu \mathrm{g} / \mathrm{dL}$, a majority $(88.2 \%)$ had their BLL greater than $5 \mu \mathrm{g} / \mathrm{dL}$ but less than $10 \mathrm{ug} / \mathrm{dL}$. The BLL cut off point recommended by CDC is $5 \mu \mathrm{g} / \mathrm{dL}$ [20]. Of the 198 children recruited in this study, $80.3 \%$ had BLL with a mean level $(9.3 \mu \mathrm{g} / \mathrm{dL})$ slightly lower than those reported by [6] in the same area. Because $60 \%$ of Kampala city habitants live in slums such as Katanga [1] where social amenities are a big problem, families in these areas live in overcrowded conditions and makeshift shelters exposed to open sewers, mosquito breeding grounds $[21,30]$ these make them vulnerable to malaria infections. This study found a high malaria infection rate especially among children in this area as compared to one reported other parts of the city and seem to agree with previous report by [3]. A majority of the study participants are reported to have elevated blood lead levels and this can be attributed to lead-contaminated runoffs from the roadside during the rainy season and dust during the dry season to peoples' homes and yards and play areas where they come into contact with children $([22,23]$. Urban soils receive large inputs of Lead from various sources including depositions from the atmosphere, household wastes, and from manure and fertilizer applications [23, 26]. Since $35 \%$ of urban dwellers in Uganda are involved in urban agriculture to supplement their food 
resources and income, propagation of Lead concentration in urban grown foodstuff is apparent [23]. Urban grown crops accumulate Lead concentrations levels above FOA thresholds and this is reported in fruits and vegetables consumed in the country [24, 25, 31] The health burden of urban agriculture in Uganda has not been assessed, and this study hypothesizes that it could be the number one important source of dietary lead in children. Because of the similarity in environmental risk factors, both malaria and BLL in children co-cluster within specific communities and households in urban areas of Uganda. The literature on the detrimental effects of elevated blood lead levels seems not to emphasize that BLL is of danger at very low levels, especially in children. This age group is most susceptible to lead poisoning [27] and there is little or no known literature about the patterns for BLL and malaria infection among children living in Kampala Uganda. We can speculate that a big percentage of urban Uganda dwellers have some levels of BLL and since it is not needed anywhere in the body system, it poses a silent health threat. The BLL indicated in this study and previous studies suggest that even at its lowest levels, the dALAD activity is compromised and this could be due to the sensitive nature of enzymes. Results from this study shows that since enzymes are very sensitive in nature of their activity, any smallest amount of blood lead is enough to affect their sensitivity. ALAD, a mitochondrial enzyme that catalyzes the formation of heme by insertion of iron into protoporphyrin IX is affected even at very low levels of blood lead in circulation. Lead blocks affect ALAD, preventing iron incorporation step into protoporphyrin IX hence the accumulation of the free erythrocyte protoporphyrin (FEP) i.e. the non-heme protoporphyrin.as well as FEP: $\mathrm{Hb} \mu \mathrm{g} / \mathrm{g}$ ratio (a lead poisoning indicator) increased exponentially with the blood Pb level in this study. Since BLL initially accumulates in erythrocytes and has a high affinity for the - SH group of enzymes, d-ALAD enzyme quickly falls victim to BLL even at very low levels. Increases in FEP levels in Lead intoxicated children even at very low BLL is indicative of the ALAD activity inhibition. Plasmodium parasites cause anemia by systematically destroying the RBCs and they seem to decrease proportionally with an increase of BLL which could be attributed to the fact that blood lead disturbs the host's iron homeostasis mechanism hence reducing the levels of RBCs important for their survival. Hepcidin (a master regulator of iron trafficking) hormone, overexpressed during lead intoxication downregulates the iron levels leading to anemia. This phenomenon is attributed to the fact that blood lead mimics iron and hence fooling hepcidin-mediated [29]. iron homeostasis that there is too much iron in circulation and if this persists, iron mobilization from the stores is shut down and decreased iron availability for erythropoiesis. Further to RBCs indiscriminate destruction by the malaria parasites, cause an imbalance in the cytokines levels and other mediators of inflammation such as hemozoin, a parasitederived polymerized heme, and IL6 one of the cytokines affected, has the capacity to affect the hepcidin expression (Cherian et al., 2008). Another cytokine of key importance affected by Plasmodium parasites 
is interferon (IFN)- $\gamma$ ) which induces macrophage production of TRAIL (TNF-related apoptosis-inducing ligand) and hence an increased activation of splenic and other macrophages for phagocytosis of red cells. It seems that progression to severe anemia is multifactorial and involve both direct and indirect destruction of parasitized and non-parasitized erythrocytes, heme synthesis inhibition (ineffective erythropoiesis) and interference of hepcidin iron regulatory activity by lead intoxication. This increased clearance of uninfected erythrocytes due to extrinsic and intrinsic changes to the RBCs enhance their recognition and phagocytosis and hence anemia. Reduced iron (substrate) availability further complicates the heme synthesis mechanism by disturbing the enzyme /substrate enzymatic reaction equation. However, this study did not find a direct relationship between high blood lead concentrations with parasite density as previously reported. We attribute the decrease in parasite density to increased iron homeostasis interference to during lead intoxication and hence less available iron important for their multiplication. A negative and strong Pearson correlation value between FEP: $\mathrm{Hb} \mu \mathrm{g} / \mathrm{g}$ and Hb levels (Table 2 and Fig.1) as compared to that between parasite density and hemoglobin levels (Fig.2) seem to support our argument that blood lead is able to block heme synthesis at much lower levels. There is moderate interaction between the three variables ( $\mathrm{FEP} / \mathrm{Hb}$, Parasite density and hemoglobin levels) after a multivariate analysis (Table 2) supports our argument. Children who participated in the study had no co-morbid diseases like HIV, sickle cell traits which could have attenuated the relationships between malaria and BLL. Simple correlation analysis between BLL and malaria parasites (Table 2 and Fig.3) in the study population seems to support our argument that BLL had a little or no direct effect on parasite density levels. To the best of our knowledge, this study represents the first reported significant association between malaria and lead poisoning during the anemia pathogenesis among the pediatric population in Uganda.

In conclusion, basing on our study findings, low blood lead is detrimental to the child's anemia status, especially during malaria infection. Blood lead does not reduce the parasite density directly but it only achieves this by limiting the amount iron in circulation for parasite to flourish on hence their natural death. Since both blood lead and plasmodium infection have similar hematological consequences, their co existence worsens the anemia status of the host.

The message from this study, therefore, is the need for improved understanding of the moderating effects of lead exposure on Plasmodium malaria, especially during anemia status.

Basing on this study's findings, we recommend a detailed anemia study on the effect of blood lead on anemia pathogenesis during malaria infection over a long period of time. 


\section{REFERENCES}

[1] https://www.academia.edu/.../SLUMS_IN_UGANDA_The_case_of_Katanga_Slum_

[2] Mghweno, L. R., Makokha, A. O., Magoha, H. S., Wekesa, J. M., \& Nakajugo, A. (2008). Environmental lead pollution and food safety around Kampala City in Uganda. J Applied Biosci, 12, 642-649.

[3] https://www.ubos.org/onlinefiles/uploads/ubos/.../Uganda_DHS_2016_KIR.

[4] https://www.indexmundi.com/facts/indicators/SH.ANM.CHLD.ZS/compare?country=ug\#country

[5] https://www.jbpub.com/.../skolnik/2e/docs/.../Malaria\%20in\%20Uganda,\%20Bauer

[6] Cusick, S. E., Jaramillo, E. G., Moody, E. C., Ssemata, A. S., Bitwayi, D., Lund, T. C., \& Mupere, E. (2018). Assessment of blood levels of heavy metals including lead and manganese in healthy children living in the Katanga settlement of Kampala, Uganda. BMC public health, 18(1), 717.

[7] Graber, L. K., Asher, D., Anandaraja, N., Bopp, R. F., Merrill, K., Cullen, M. R. \& Trasande, L. (2010). Childhood lead exposure after the phaseout of leaded gasoline: an ecological study of school-age children in Kampala, Uganda. Environmental health perspectives, 118(6), 884-889.

[8] https://www.voanews.com/a/pollution-is-sil[1] ent-killer-in-uganda/2648372.html

[9] Piomelli, S. (2002). Childhood lead poisoning. Pediatric Clinics of North America, 49(6), 1285-304.

[10] Bergdahl, I. A., Grubb, A., Schütz, A., Desnick, R. J., Wetmur, J. G., Sassa, S., \& Skerfving, S. (1997). Lead binding to $\delta$-aminolevulinic acid dehydratase (ALAD) in human erythrocytes. Pharmacology \& toxicology, 81(4), 153-158.

[11] Loréal, O., Cavey, T., Bardou-Jacquet, E., Guggenbuhl, P., Ropert, M., \& Brissot, P. (2014). Iron, hepcidin, and the metal connection. Frontiers in pharmacology, 5, 128.

[12] Qian, Y., \& Tiffany-Castiglioni, E. (2003). Lead-induced endoplasmic reticulum (ER) stress responses in the nervous system. Neurochemical research, 28(1), 153-162.

[13] Oppenheimer, S. J. (1989). Iron and infection: the clinical evidence. Acta Paediatrica, 78, 53-62.

[32] https://www.nape.or.ug/publications/chemical-management/54-lead-paint-elimination-report/file

[14] Mahaffey, K. R., \& Annest, J. L. (1986). Association of erythrocyte protoporphyrin with blood lead level and iron status in the Second National Health and Nutrition Examination Survey, 1976-1980. Environmental Research, 41(1), 327-338.

[15] Snow, R. W., Guerra, C. A., Noor, A. M., Myint, H. Y., \& Hay, S. I. (2005). The global distribution of clinical episodes of Plasmodium falciparum malaria. Nature, 434(7030), 214.

[16] Marsh Jr, W. L., Nelson, D. P., \& Koenig, H. M. (1983). Free erythrocyte protoporphyrin (FEP) I. Normal values for adults and evaluation of the hematofluorometer. American journal of clinical pathology, 79(6), 655-660.

[17] Flora, G., Gupta, D., \& Tiwari, A. (2012). Toxicity of lead: a review with recent updates. Interdisciplinary toxicology, 5(2), 47-58.

[18] Trape, J. F. (1985). Rapid evaluation of malaria parasite density and standardization of thick smear examination for epidemiological investigations. Transactions of the Royal Society of Tropical Medicine and Hygiene, 79(2), 181184.

[19] Piomelli, S. (1973). A micro method for free erythrocyte porphyrins: the FEP test. The Journal of laboratory and clinical medicine, 81(6), 932-940. 
[20] Wheeler, W., \& Brown, M. J. (2013). Blood lead levels in children aged 1-5 years-United States, 19992010. MMWR. Morbidity and mortality weekly report, 62(13), 245.

[21] Mwangi, T. W., Bethony, J. M., \& Brooker, S. (2006). Malaria and helminth interactions in humans: an epidemiological viewpoint. Annals of Tropical Medicine \& Parasitology, 100(7), 551-570.

[22] Kakulu, S. E. (2003). Trace metal concentration in roadside surface soil and tree back: A measurement of local atmospheric pollution in Abuja, Nigeria. Environmental Monitoring and Assessment, 89(3), 233-242.

[23] Nabulo, G., Oryem-Origa, H., \& Diamond, M. (2006). Assessment of lead, cadmium, and zinc contamination of roadside soils, surface films, and vegetables in Kampala City, Uganda. Environmental Research, 101(1), $42-52$.

[24] Eriyamremu, G. E., Asagba, S. O., Akpoborie, I. A., \& Ojeaburu, S. I. (2005). 1962361. Evaluation of lead and cadmium levels in some commonly consumed vegetables in the Niger-Delta oil area of Nigeria. Bulletin of environmental contamination and toxicology, 75(2), 278-283.

[25] Maduabuchi, J. M., Nzegwu, C. N., Adigba, E. O., Aloke, R. U., Ezomike, C. N., Okocha, C. E., ... \& Orisakwe, O. E. (2006). Lead and cadmium exposures from canned and non-canned beverages in Nigeria: a public health concern. Science of the Total Environment, 366(2-3), 621-626.

[26] Mielke, H. W., Gonzales, C. R., Smith, M. K., \& Mielke, P. W. (1999). The urban environment and children's health: soils as an integrator of lead, zinc, and cadmium in New Orleans, Louisiana, USA. Environmental research, 81(2), [9] 117-129.

[27] https://wonder.cdc.gov/wonder/prevguid/p0000029/p0000029.asp

[28] Nriagu, J., Oleru, N. T., Cudjoe, C., \& Chine, A. (1997). Lead poisoning of children in Africa, III. Kaduna, Nigeria. Science of the Total Environment, 197(1-3), 13-19.

[29] Cheria[1] n, S., Forbes, D. A., Cook, A. G., Sanfilippo, F. M., Kemna, E. H., Swinkels, D. W., \& Burgner, D. P. (2008). An insight into the relationships between hepcidin, anemia, infections and inflammatory cytokines in pediatric refugees: a cross-sectional study. PloS one, 3(12), e4030.

[30] Worrall, E., Basu, S., \& Hanson, K. (2005). Is malaria a disease of poverty? A review of the literature. Tropical Medicine \& International Health, 10(10), 1047-1059.

[31] Obi, E., Akunyili, D. N., Ekpo, B., \& Orisakwe, O. E. (2006). Heavy metal hazards of Nigerian herbal remedies. Science of the total environment, 369(1-3), 35-41. 